\title{
Optical properties of pyrazine derivatives compared with their s-triazine analogs
}

\author{
Yan $\mathrm{Li}^{\mathrm{a}}{ }^{\mathrm{*}}$ Xiao-Shuang $\mathrm{Ma}^{\mathrm{b}}$ \\ ${ }^{1}$ School of Chemistry and Pharmaceutical Engineering, QiLu University of Technology, Jinan \\ 250353, China, \\ aemail: yanlichem@163.com, ${ }^{b}$ xsma@163.com
}

Keywords: fluorescence; pyrazine; branching pattern; absorption

\begin{abstract}
A series of aryl-substituted pyrazine derivatives, as well as their s-triazine analogues, have been synthesized. For the three-branched compounds, the pyrazine derivatives show strong emission, while its s-triazine analogue TSTA shows too weak emission to be detected. Furthermore, the two-branched pyrazine with para-branching pattern exhibits much higher emission intensity than its analogue which attaches two branches in meta-position. These results indicate great effects of branching pattern on fluorescence intensity for multi-branched compounds with six-membered aromatic center.
\end{abstract}

\section{Introduction}

The six-membered N-heterocyclic aromatic ring, such as pyridine, pyrazine and triazine, et al, has been widely adopted as electron-withdrawing group to build the intramolecular charge transfer (ICT) molecules [1-2]. With various optoelectronic properties, the ICT compounds show potential applications in many fields, such as two-photon absorption materials [3-5], fluorescence chemical sensors [6-8] and organic light-emitting diodes [9-10], et al. In our previous work, several triazine derivatives were synthesized to be as two-photon absorption materials. We found that they show relatively low quantum yields of fluorescence [11], which limits their application as TPA materials. The low quantum yields may be attributed to the meta-branching pattern in triazine derivatives, because it is well known that the electron delocalization among the branches in meta position is weak. Therefore, designing multi-branched structure with ortho- or para-branching pattern is helpful to obtain higher quantum yields of fluorescence than its of meta-branching analogue.

Like s-triazine, pyrazine is also a six-membered aromatic system. The difference between them is that, only two nitrogen atoms lie in the para positions for pyrazine, whereas three nitrogen atoms in meta-positions for s-triazine. Since the larger electronegativity of nitrogen atom, s-triazine is obviously a stronger electron acceptor than pyrazine. Generally speaking, a stronger donor or acceptor will cause stronger intramolecular charge transfer (ICT), which can lower the energy gap between HOMO and LUMO, and is usually favors for absorption and emission [12-13]. Therefore, It seems that the pyrazine derivatives should have weak optical properties than triazine derivatives. Maybe this is the reason why little attention has been paid to the pyrazine derivatives in this erea. However, unlike the s-triazine, pyrazine allows the branches attaching to the ortho/para-position to each other. Such a branching pattern usually makes for good electron delocalization among branches.

In this paper, we have designed and synthesized a series of multi-branched pyrazine derivatives with different branching patterns (seen in Scheme 1), including two-branched (I and II) and three-branched (III) compounds. For compounds II and III, any one of the branches has a counterpart in its ortho or para position, whereas for compound I, two branches are in meta positions to each other. To compare the properties of pyrazine derivatives with their triazine analogues, we also synthesized a three-branched triazine derivatives (TSTA) according to previous method(10). Their optical properties are studied in this work. 


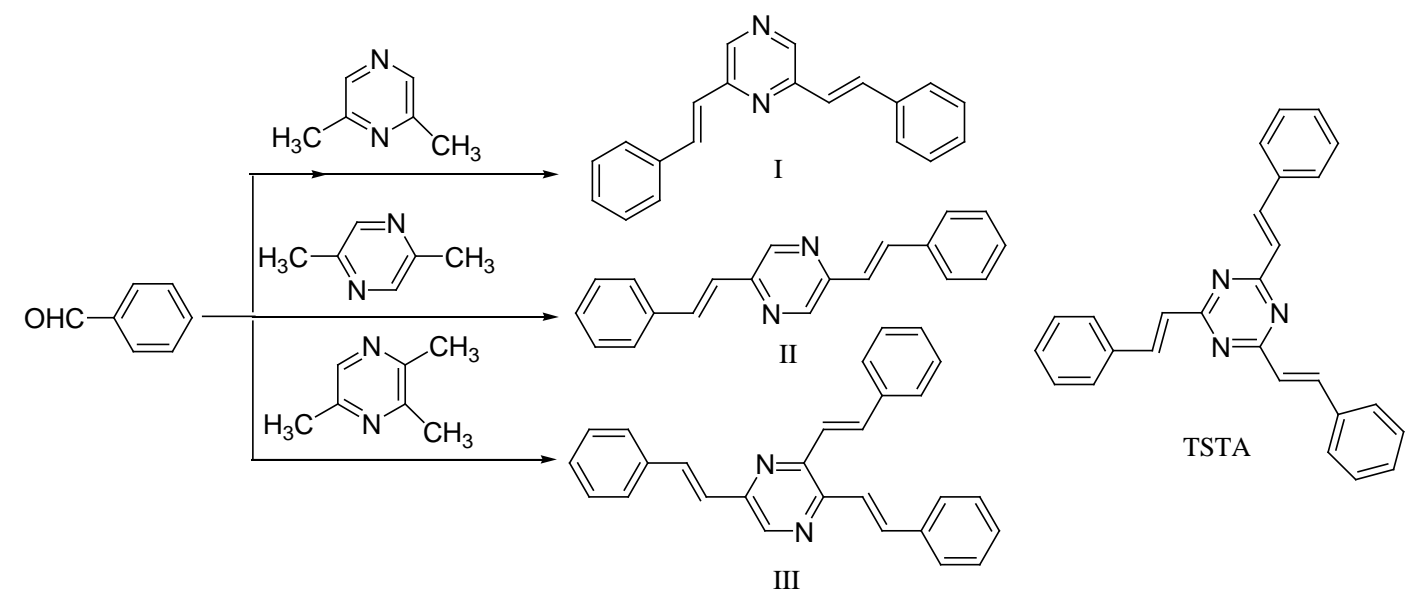

Scheme 1. Synthesis and molecule schemes of compounds I, II, III and TSTA

\section{Experimental}

Measurements.The melting points were measured by a SGW X-4 Melting Point Tester and 1HNMR spectrum were determined by $400 \mathrm{MHz}$ using Bruker. Elemental analyses were carried out on PE2400. The mass spectra were obtained by ABI 4000 MSD. Using a Hitachi U-3500 UV/Vis-IR spectrophotometer detected the one-photon absorption (OPA) spectra. The One-photon excited fluorescence (OPEF) spectra measurements were performed using a VARIAN Cary Eclipse Fluorescence Spectrophotometer at the exciting wavelength of 364, 385, 350 and $340 \mathrm{~nm}$ for compound I, II, III and TSTA, respectively. The OPEF quantum yields $\Phi$ was determined according to the reported method using coumarine 307 in methanol $\left(C=1 \times 10^{-5} \mathrm{~mol} \mathrm{~L}^{-1}\right)$ as the reference compound [14].

Synthesis of compound I. Under the temperature of $180{ }^{\circ} \mathrm{C}$, 2, 6-dimethylpyrazine (3.24 g, 0.03 mol) in $10 \mathrm{~mL}$ EtOH was added dropwise into the mixture of benzaldehyde ( $40 \mathrm{ml}, 0.35 \mathrm{~mol})$ and phthalic anhydride ( $2.36 \mathrm{~g}, 0.016 \mathrm{~mol})$ in $1 \mathrm{hr}$. Then the reaction mixture was refluxed for further 15 hrs. The mixture was cooled to room temperature, and then $50 \mathrm{~mL}$ chloroform was added to resolve it. After extracting the mixture by sodium hydroxide solution, the crude product was obtained and then purified by column chromatography on silica gel using benzene/petroleum ether as eluent. The product was recrystallized and yellow crystals were obtained.

I: m.p. $130-131{ }^{\circ} \mathrm{C} .{ }^{1} \mathrm{H}$ NMR(CDCl $\left.3,400 \mathrm{MHz}\right) \delta(\mathrm{ppm}): 8.43(\mathrm{~s}, 2 \mathrm{H}), 7.81(\mathrm{~d}, 2 \mathrm{H}, J=16.0), 7.59(\mathrm{~d}$, $4 \mathrm{H}, J=7.2), 7.37\left(\mathrm{t}, 4 \mathrm{H}, J_{1}=7.2, J_{2}=7.6\right), 7.31\left(\mathrm{t}, 2 \mathrm{H}, J_{1}=J_{2}=7.2\right), 7.17$ (d, 2H, $\left.J=16.0\right)$. Anal. Calcd for $\mathrm{C}_{20} \mathrm{H}_{16} \mathrm{~N}_{2}$ (284.35): C, 84.48; H, 5.67; N, 9.85. Found: C, 83.90; H, 5.76; N, 9.55. MS data, m/z (\%): 285.3 (M+1, 100), 279.7(2.50), 126.3(1.25).

Synthesis of compound II and III. Compound II and III were prepared according to the same procedures as compound I, except that 2,5-dimethylpyrazine was substituted for 2,6-dimethylpyrazine (3.24 g, $0.03 \mathrm{~mol}$ ) to obtain II, and 2,3,5-trimethylpyrazine was substituted for 2,6-dimethylpyrazine $(3.67 \mathrm{~g}, 0.03 \mathrm{~mol}$ ) to obtain III, respectively. The colour of II was yellow-green while III was bright yellow.

II: m.p. $232-234{ }^{\circ} \mathrm{C} .{ }^{1} \mathrm{H}$ NMR( $\left(\mathrm{CDCl}_{3}, 400 \mathrm{MHz}\right) \delta(\mathrm{ppm}):$ 8.65(s, 2H), 7.82(d, 2H, $\left.J=16.0\right), 7.64$ (d, $4 \mathrm{H}, J=7.2$ ), 7.44 (t, 4H, $\left.J_{1}=7.2, J_{2}=7.6\right), 7.38\left(\mathrm{t}, 2 \mathrm{H}, J_{1}=J_{2}=7.2\right), 7.25$ (d, $\left.2 \mathrm{H}, J=16.0\right)$. Anal. Calcd for $\mathrm{C}_{20} \mathrm{H}_{16} \mathrm{~N}_{2}$ (284.35): C, 84.48; H, 5.67; N, 9.85. Found: C, 83.80; H, 5.78; N, 9.38. MS data, $\mathrm{m} / \mathrm{z}(\%): 285.3(\mathrm{M}+1,100), 59.8$ (6.83).

III: m.p. 176-177 ${ }^{\circ} \mathrm{C} .{ }^{1} \mathrm{H} \mathrm{NMR}\left(\mathrm{CDCl}_{3}, 400 \mathrm{MHz}\right) \delta(\mathrm{ppm}): 8.56(\mathrm{~s}, 1 \mathrm{H}), 8.04(\mathrm{~d}, 1 \mathrm{H}, J=15.6)$, 7.96 (d, 1H, $J=16.0), 7.88(\mathrm{~d}, 1 \mathrm{H}, J=16.4), 7.72-7.72(\mathrm{q}, 6 \mathrm{H}), 7.67-7.52(\mathrm{q}, 2 \mathrm{H}), 7.48-7.30(\mathrm{~m}, 9 \mathrm{H})$, 7.35 (d, 2H, $J=15.2$ ). Anal. Calcd for $\mathrm{C}_{28} \mathrm{H}_{22} \mathrm{~N}_{2}$ (386.49): C, 87.01; H, 5.74; N, 7.25. Found: C, 87.19; H, 6.03; N, 6.04. MS data, m/z (\%): 387.4 (M+1, 100), 285.0 (5.01), 279 (1.15), 101.9 (0.77). 


\section{Results and Discussions}

The properties of the linear absorption and emission spectra are shown in Table I, Fig. 1 and Fig. 2. As is observed from Fig. 1, each pyrazine derivative has two absorption peaks in the UV-VIS range. The peak at longer wavelength corresponds to ICT excitation, whereas the shorter absorption peak is attributed to localized excitation. With the increase of the solvent polarity (toluene < chloroform $<$ ethanol), all the longest absorption peak positions [ $\left.\lambda^{\mathrm{a}(1)}\right]$ of I, II and III show very small shifts $(<6 \mathrm{~nm}$, seen in Table 1), indicating small polarity of these compounds in the ground state. It is easy to understand that, with two or three branches sharing one acceptor and without strong electron donor at the end of each branch, these molecules can hardly have large polarity.

Scheme 1. Synthesis and molecule schemes of compounds I, II, III and TSTA

\begin{tabular}{lcccccccccccc}
\hline & \multicolumn{3}{c}{$\boldsymbol{i}_{\boldsymbol{\lambda} \mathbf{a}(\mathbf{1})}$} & \multicolumn{3}{c}{$\boldsymbol{i i}_{\boldsymbol{\varepsilon}}$} & \multicolumn{4}{c}{$\boldsymbol{i i i}_{\boldsymbol{\lambda} \mathbf{e}(\mathbf{1})}$} & \multicolumn{3}{c}{${ }^{\text {iv } \boldsymbol{\Phi}}$} \\
\cline { 2 - 13 } & tolu & chlo & etha & tolu & chlo & etha & tolu & chlo & etha & tolu & chlo & etha \\
\hline II & 386 & 383 & 380 & 6.12 & 6.14 & 6.26 & 431 & 435 & 451 & 14.45 & 12.79 & 12.77 \\
III & 408 & 405 & 404 & 3.23 & 3.33 & 3.52 & 462 & 476 & 484 & 18.81 & 18.23 & 15.54 \\
TSTA & 326 & & & 7.20 & & & 384 & & & 1.48 & \\
\hline
\end{tabular}

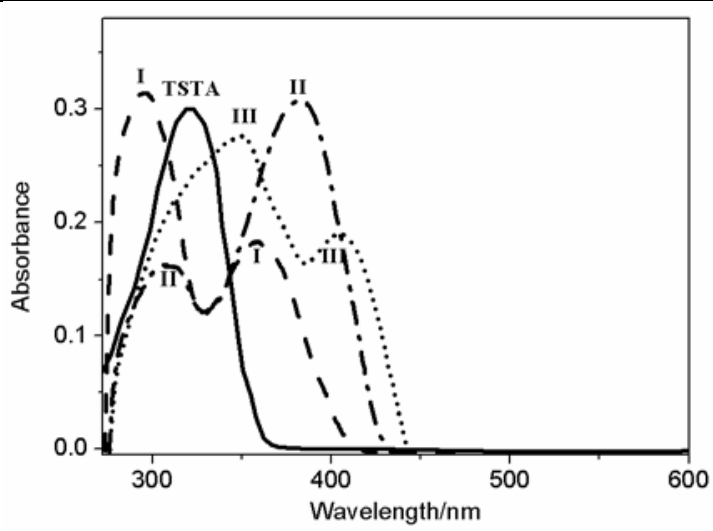

Fig.1. The one-photon absorption spectra of compounds I, II, III and TSTA in chloroform $\left(5 \times 10^{-6} \mathrm{~mol} \mathrm{~L}^{-1}\right)$.

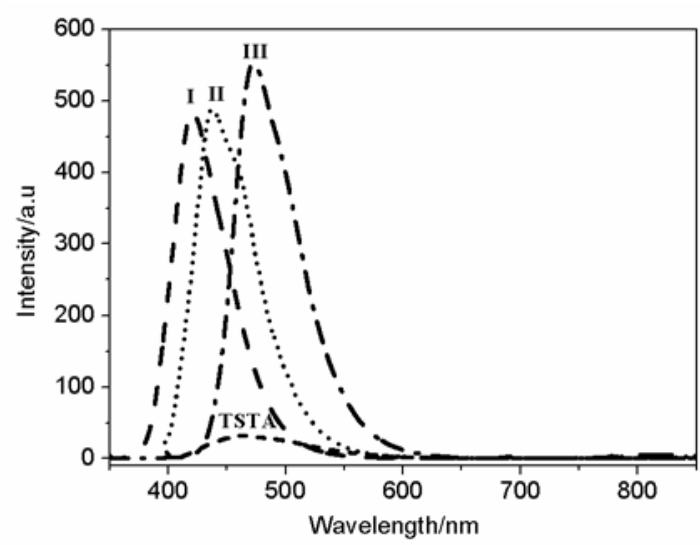

Fig.2. The one-photon excited fluorescence spectra of all the compounds I, II, III and TSTA in chloroform $\left(5 \times 10^{-6} \mathrm{~mol} \mathrm{~L}^{-1}\right)$

Unlike the case of absorption spectra, the emission spectra of these compounds show regular red-shifts with the solvent polarity increasing, implying larger polarity of molecule in the excited state than in the ground state. For example, the emission peak position [ $\left.\lambda^{\mathrm{e}(1)}\right]$ of compound III red-shifts by $22 \mathrm{~nm}$ when it goes from toluene to ethanol. Such red-shift of emission spectra corresponds to the so-called 'positive solvatochromism', which is attributed to the ICT transition [15] . It is noteworthy that, although both compound I and II are two-branched compounds, the 
emission and absorption spectra show obvious red-shifts from I to II (12 nm for absorption, $16 \mathrm{~nm}$ for emission). This is a clear evidence that meta-branching pattern produces much weaker electronic coupling between branches than para-branching pattern. Such a result is in agreement with the theoretical work by Beljonne et al, which proved the electronic coupling between the branches in meta-position was weak [16].

As can also be seen in Scheme 1 and Table 1, from I to III, with the increase of ortho/para-branching number $(0 \rightarrow 2)$, both $\lambda^{\mathrm{a}(1)}$ and $\lambda^{\mathrm{e}(1)}$ shift to the longer wavelength remarkably. This may be attributed to the extended delocalization by more branches in ortho/para positions. The extended delocalization results in the reducing of the energy gap between the ground and the excited state.

Another evidence to prove the great effects of branching pattern on the optical property can be obtained by comparing the emission spectra of compound III with that of TSTA. Both TSTA and III have three vinylphenyl branches, but they have different electron acceptor and branching pattern. $s$-Triazine is a stronger electron acceptor than pyrazine, therefore, it seems TSTA should have much red-shifted absorption and emission spectra than compound III due to its stronger ICT effect. However, the results in Table 1 show that both $\lambda^{\mathrm{a}(1)}$ and $\lambda^{\mathrm{e}(1)}$ of compound III are much longer than TSTA, implying a more extended delocalization in III. These abnormal results experimentally prove that ortho- and para-branching are superior to meta-branching from the viewpoint of electronic coupling between branches. It can also be found in Fig. 2 that compound III emits much stronger fluorescence than TSTA. Table 1 also lists the much smaller $\Phi$ of TSTA (1.48\%) than that of compound III (18.23\%). The strong electronic coupling between the branches in III may be responsible for its strong emission.

\section{Conclusion}

Pyrazine derivatives exhibit much stronger emission intensity than their s-triazine analogues, The para-/ortho-branching pattern, which means good electron coupling between branches, plays an important role in the enhancement of optical properties. This research may be useful for designing new molecules with strong emission.

\section{Acknowledgement}

We gratefully acknowledge the National Natural Science Foundation of China (NO.21276149), the promotive research fund for young and middle-aged scientists of Shandong Province (BS2014NJ012) and the Program for Scientific Research Innovation Team in Colleges and Universities of Shandong Province.

\section{References}

[1] A. L. Wang, D. Zhou, Y. N. Chen, J. J. Li, H. X. Zhang, Y. L. Zhao and H. B. Chu,Crystal structure and photoluminescence of europium, terbium and samarium compounds with halogen-benzoate and 2,4,6-tri(2-pyridyl)-s-triazine, Journal of Luminescence, 2016(177) 22-30.

[2] T. Matulaitis, N. Kostiv, J.V. Grazulevicius, L. Peciulyte, J. Simokaitiene, V. Jankauskas, B. Luszczynska, J. Ulanski, Synthesis and properties of bipolar derivatives of 1,3,5-triazine and carbazole, Dyes and Pigments, 2016(127) 45-48.

[3] B.A. Reinhardt, L.L. Brott, S.J. Clarson, A.G. Dillard, J.C. Bhatt and R. Kannan, Highly Active Two-Photon Dyes: Design,synthesis,and characterization toward application, Chem. Mater,1998(10)1863-1874.

[4] Z.Q. Liu, Q. Fang, D. Wang, D.X. Cao, G. Xue, W.T. Yu, and H. Lei, Trivalent boron as an acceptor in donor- $\pi$-acceptor-type compounds for single-and two-photon excited f luorescence, Chem. Eur. J., 2003(9)5074-5084. 
[5] Y. Ren, X.Q. Yu, D.J. Zhang, D. Wang, M.L. Zhang, G.B. Xu, X. Zhao, Y.P. Tian, Z.S. Shao and M.H. Jiang, "Synthesis, structure and properties of a new two-photon photopolymerization initiator,” J. Mater. Chem., 2002(12)3431-3437.

[6] D. Patra, A.K. Mishra, Fluorescence quenching of benzo[k]fluoranthene in poly(vinyl alcohol) film: a possible optical sensor for nitro aromatic compounds, Sensors and Actuators, 2001(B80) 278-282.

[7] J.S. Kim, D. Tyler, A. Rose, Z.G. Zhu and T.M. Swager, Directing energy transfer within conjugated polymer thin films, J. Am.Chem.Soc., 2001(123)11488-11489.

[8] J. S. Yang, T.M. Swager, Porous shape persistent fluorescent polymer films: an approach to TNT sensory materials, J. Am. Chem. Soc. 1998(120) 5321-5322.

[9] C.F.O. Grae, G.B. Silva, F.N. Äuesch, L. Zuppiroli, Transport and recombination in organic light-emitting diodes studied by electrically detected magnetic resonance, Eur. Phys. J. E., 2005(18)21-28.

[10] L. He, L. Duan, J. Qiao, D.Q. Zhang, L.D. Wang, Y. Qiu, Efficient blue-green and white organic light-emitting diodes with a small-molecule host and cationic iridium complexes as dopants, Appl Phys., 2010(a100)1035-1040.

[11] Y.Z. Cui, Q. Fang, G. Xue, G.B. Xu, L. Yin, and W.T. Yu, Cooperative enhancement of two-photon absorption of multibranched compounds with vinylenes attaching to the s-triazine core, Chem. Letters, 2005(34)644-645.

[12] M. Albota, D. Beljanne, J. L. Brédas, J.E. Ehrlich, J.Y. Fu, A.A. Heikal, A.E. Hess, T.Kogei, M.D. Levin, S.R. Marder, D. McCord-Marughon, J.W. Perry, H. Röchel, M. Rumi, G. Subramaniam, W.W. Webb, X.-L. Wu, S. Xu, Design of organic molecules with large two-photon absorption cross sections, Science New Series, 1998(281)1653 -1656.

[13] S.J. Chung, K.S. Kim, T.C. Lin, G.S. He, J. Swiatkiewicz, and P.N. Prasad, Cooperative enhancement of two-photon absorption in multi-branched structures, J. Phys. Chem., 1999(b103)10741-10745.

[14] J.N. Demas and G.A. Crosby, Measurement of photoluminescence quantum yields. Review, J. Phys. Chem., 1971(75)991-1024.

[15] J.L. Oudar, D.S. Chemla, Hyperpolarizabilities of the nitroanilines and their relations to the excited state dipole moment, J. Chem. Phys., 1977(66)2664-2668.

[16] D. Beljonne, W. Wenseleers, E. Zojer, Z. Shuai, H. Vogel, S.J.K. Pond, J.W. Perry, S.R. Marder, and J.-L. Bredas, Role of dimensionality on the two - photon absorption response of conjugated molecules: the case of octupolar compounds, Adva. Func. Mater., 2002(12)631-641. 